\title{
HEALTHCARE QUALITY INNOVATION AND PERFORMANCE \\ THROUGH PROCESS ORIENTATION: EVIDENCE FROM GENERAL \\ HOSPITALS IN SWITZERLAND
}

\author{
Anne Cleven, Tobias Mettler, Peter Rohner, Robert Winter \\ Institute of Information Management, University of St. Gallen, Unterer Graben 21, CH- \\ 9000 St. Gallen, Switzerland
}

Citation: Cleven, A; Mettler, T.; Rohner, P., Winter R. "Healthcare Quality Innovation and

Performance through Process Orientation: Evidence from General Hospitals in

Switzerland," Technological Forecasting and Social Change, forthcoming, doi: doi:10.1016/j.techfore.2016.07.007

\begin{abstract}
As a primary factor of technological innovation, process orientation contributes significantly to an organization's overall productivity and quality improvement. While this proposition has been confirmed for profit-oriented organizations of various industries, little research exists that validates the same statement in the healthcare sector. This paper proposes and evaluates a theoretical model that investigates the effect of process orientation on hospitals' competitiveness and performance. The concept of the balanced scorecard is applied to comprehensively cover all facets that constitute healthcare quality innovation. A set of hypotheses is proposed conceptualizing the direct and indirect effects of process orientation on hospitals' performance (identified as patient satisfaction and financial performance) through an increase of integral competitiveness (identified as workforce conditions, operational performance and clinical quality). The model is empirically tested by means of a questionnaire-based survey among clinical and administrative management of hospitals in Switzerland. 145 complete questionnaires from 129 hospitals are analyzed. Statistical results affirm that process orientation significantly enhances hospital performance. Workforce conditions and clinical quality prove to have a significant positive effect on patient satisfaction, whereas the hypothesized positive effect of operational efficiency on patient satisfaction is not supported. Moreover, results attest the positive effect of workforce conditions and operational efficiency on financial performance, while rejecting the effect of clinical quality on financial performance.
\end{abstract}

Keywords. Clinical quality; hospital performance; implementation science; process orientation; technology innovation. 


\section{INTRODUCTION}

With hospitals increasingly being pushed into competitive market structures, hospital management has been vigorously searching for managerial solutions to streamline their operations in order to reduce cost and yet to maintain a high quality of care (Bragato and Jacobs, 2003; Pai and Huang, 2011). Hospitals pursue both transparency and comparability of both costs and quality of inpatient care (Donahue and Zeckhauser, 2011). Process orientation might be one solution for hospitals to achieve the two goals, though there are a few empirical researches available on performance-related benefits of process orientation in hospitals (Vera and Kuntz, 2007; Yarmohammadian et al., 2014). In this regard, our research confirms that the adoption of process orientation has a positive impact on the internal performance of a hospital (Hung, 2006; Kohlbacher, 2010; Skrinjar et al., 2008). Furthermore, our findings imply that a positional advantage of the hospital may emerge through which it may be able to attract more capable and motivated personnel (Cleven et al., 2014).

According to the studies in other industries, such as manufacturing, finance or logistics, process orientation is recognized as an organizational capability that is related to continuous quality improvement and performance increases (Mettler and Rohner, 2009a; Zairi, 1997). In the healthcare sector, process orientation has been introduced in various models (Axelsson et al., 2014; Cleven et al., 2014; Leggat et al., 2015). Our research is uniquely designed to connect process orientation in hospitals with their performance: qualitative performance and financial performance. The measuring of hospital performance, in contrast, has long been subject to intense research (Fottler, 1987; Griffith et al., 2002; Marley et al., 2004; Mettler and Rohner, 2009b). Among many approaches to measure performance, the Balanced Scorecard (BSC) has become common practice for measuring and guiding hospital performance (Albertsen and Lueg, 2014; Chang et al., 2008; Mutale et al., 2014;Walker and Dunn, 2006; Wu and Chen, 2014). Hence, our study builds 
upon the concept of BSC and develops a set of hypotheses about how process orientation affects hospital performance. Particularly, we designed to test if the link between the workforce conditions and clinical quality has an effect on patient satisfaction and operational efficiency.

Given the specific context of the Swiss healthcare sector, which is impaired by a case-based remuneration scheme through which hospitals have to finance their running costs and long-term infrastructure investments, a purpose of this study is to perceive process orientation also as an important antecedent of financial performance. We therefore also tested the relationships among process orientation and overall outcomes of hospital performance.

In what follows we will describe a set of hypotheses about how process orientation affects important outcomes of hospital performance. We then present evidence from a field study that we designed to test these hypotheses. The results show that workforce conditions and clinical quality prove to have a significant positive effect on patient satisfaction, whereas the hypothesized positive effect of operational efficiency on patient satisfaction is not supported. Our study findings also show a positive effect of workforce conditions and operational efficiency on financial performance, while we could not find a significant relation between clinical quality and financial performance.

\section{CONCEPTUAL BACKGROUND AND PRIOR RESEARCH}

\subsection{Process orientation in hospitals}

Hospitals have traditionally been structured along clinical departments and specialized functional units. Process orientation in contrast aims at a cross-functional, customeroriented paradigm of organizational thinking and working (McCormack, 2001; Skrinjar et al., 2008). The introduction of process orientation frequently results in both, technological and organizational process innovations. Accordingly, researchers have often investigated the effects of process orientation on organizational performance (Kohlbacher, 2010). 
These studies have shown that process orientation supports cost reductions; improvement of customer satisfaction, quality and productivity; and a decrease in cycle times.

The main approaches to foster process orientation in hospitals are patient-focused care (Hurst, 1996), clinical pathways (Bragato and Jacobs, 2003), and the application of quality management approaches like Lean and Six Sigma (Fischman, 2010) but also-from a technological perspective-the implementation of workflow systems and health care analytics (Mettler and Vimarlund, 2009). A series of three research projects empirically tests the causal relationships of the Malcolm Baldrige National Quality Award (MBNQA), a U.S. award promoting quality awareness (Goldstein and Schweikhart, 2002; Marley et al., 2004; Meyer and Collier, 2001). As shown by Meyer and Collier (2001), a significant effect of process management on patient satisfaction was found. The hypothesized effect of process management on organizational performance, however, is not supported. Vera and Kuntz (2007) make use of the data envelopment method to validate their proposition that a process-based hospital organization (defined through the constructs process optimization, clinical pathways, multi-disciplinary teamwork, activity-based costing, profit centers, and performance-based pay) has a positive effect on efficiency. The authors find a significant linear relationship between process-oriented organizational design and hospital efficiency. All in all, as has likewise been stated by Vera and Kuntz (2007), empirical quantitative research on process orientation in hospitals is fairly scarce and does thus far not reflect the increased practitioner interest.

\subsection{Hospital performance measurement}

From a management perspective performance is frequently perceived as valued contribution to reach the goals of an organization. Contributions to performance can be made by individuals or groups of employees as well as by external groups. Using this perspective, Spangenberg (1994) defined performance management as a sequence of activities for (i) 
planning the value creation, (ii) taking action to control value creation, (iii) measurement of value contribution, and finally (iv) rewarding the value contribution.

But what is performance in the context of healthcare? As the goals of healthcare organizations often are not clearly defined and the value of healthcare service delivery is difficult to allocate, performance management literature tends to use the three E's - economy, efficiency, and effectiveness - to define performance for the non-for-profit context (Carter et al., 1995; Flynn, 1997; Rouse, 1999). Performance therefore has to be perceived as a multidimensional phenomenon, where the financial, respectively value perspective (economy) is only one dimension of the whole. It is also necessary to consider patientrelated aspects (effectiveness) and procedural and knowledge-related aspects (efficiency). According to this, potential areas where performance in healthcare can be measured are:

- Healthcare financial strength (economy): Revenue optimization, productivity improvement, streamlining claims processing, waste and cost control, activity-based costing.

- Healthcare operations and technology (economy): Quality and technology management and measurement, collaboration opportunities, agility improvement, working capital and asset management.

- Healthcare people development (efficiency): Provider experience measurement, provider loyalty and the voice of the provider analysis, learning and growth measures, innovation, knowledge, culture and intangible value analytics.

- Patient service and satisfaction (effectiveness): Including patient experience, engagement, delight, loyalty and relationship measurement, as well as the most important of all - measuring and tracking the voice of the patient.

- Healthcare marketing (effectiveness): Measuring and developing the growing importance of healthcare branding, reputation and trust management, patient/customer segmentation, patient profitability and patient lifetime value. 
Performance management in hospitals is not only aiming at the systematic generation and control of the organization's economic value but also at the optimization of the efficiency and effectiveness of service delivery. Therefore performance management, like other management approaches, only can be implemented successfully, if strategic planning is closely linked to operational execution and controlling (Melchert et al., 2004). This interdependency between strategy and operations is illustrated in Fig. 1.

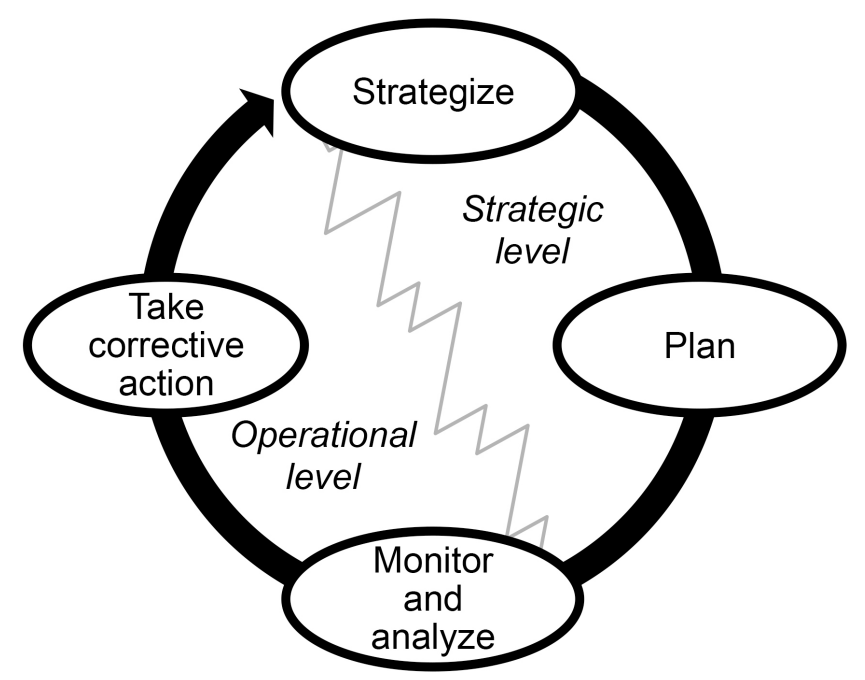

Fig. 1. Performance management life cycle (Mettler and Rohner, 2009b)

The BSC concept inherently makes use of strategic and operational considerations. It is a multidimensional framework for measuring and managing organizational performance on the basis of both financial and non-financial indicators (Kaplan and Norton, 1992). A plenitude of qualitative (Gumbus et al., 2003; Kershaw and Kershaw, 2001) and some quantitative research (Chan and Seaman, 2009; Lovaglio, 2011; Yang and Tung, 2006) on the use of the BSC in the healthcare sector has been carried out. An analysis of the current literature frequently presents process orientation as an antecedent of hospital performance although the causal relationship of the BSC in the hospital sector is quite ambiguous and partly fragmentary. In the subsequent sections we develop a research model and then 
present evidence from a field study in order to substantiate the currently weak links discussed in the literature.

\section{THEORY AND HYPOTHESES}

An influential theoretical framework that has frequently been employed for examining how organizations achieve competitive advantages and realize superior performance is the dynamic capability (DC) theory - filling the BSC's gap of "a reliable theoretical base" (Nørreklit, 2003).

This study employs the DC theory to conceptualize the effect of process orientation on hospital performance and to overcome the deficiencies associated with the cause-effectlogic of the BSC. The latter is accomplished by structuring the BSC dimensions along two dimensions: (i) the hospital's integral competitiveness and (ii) hospital performance. The resulting research model is shown in Fig. 2.

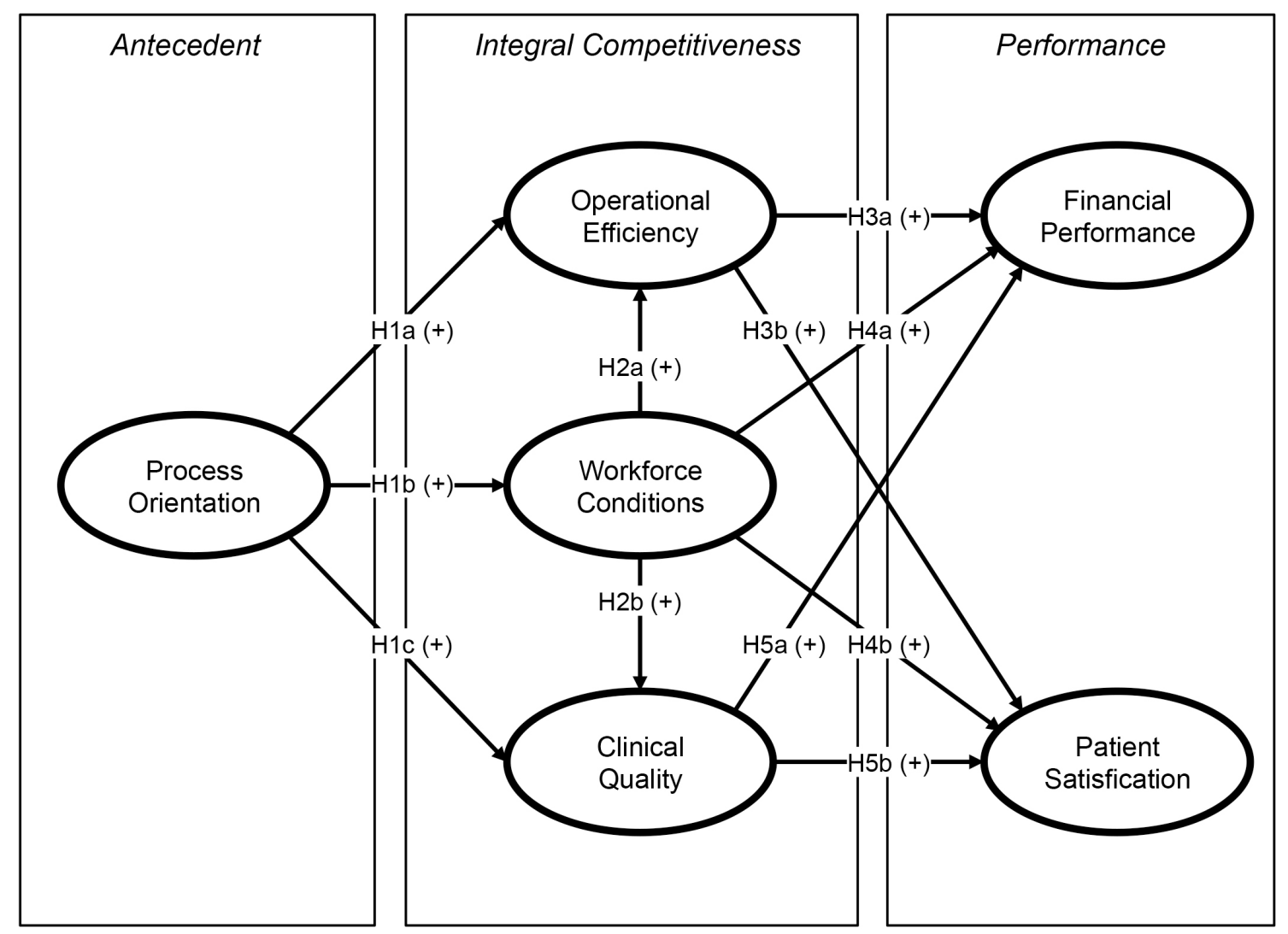

Fig. 2. Research model 
Following prior research (Chen et al., 2009; Gemmel et al., 2008; Vera and Kuntz, 2007), process orientation is defined as the degree to which the staff of a hospital thinks and works truly flow-oriented across all clinical and support functions and is committed to continuous improvement.

According to Yang and Tung (2006), operational efficiency has been one of the most frequently identified factors for competitive advantage and one of the most often studied factors in the healthcare BSC literature. Efficiency is included in this study as a construct reflecting the degree to which a hospital works both fluently and steadily and is capable of realizing short waiting times and lengths of stay. Besides operational efficiency, Veillard et al. (2005) as well as Wicks et al. (2007) remark that personnel largely determines a hospital's integral competitiveness. For the purpose of this study, the construct regarding workforce conditions is defined as the degree to which a hospital's personnel is competent and shows a high employee satisfaction. While some studies regard quality of care as the ultimate outcome of hospital performance or the end itself (West, 2001), the study at hand views clinical quality as integral competitiveness that allows hospitals to realize better overall performance. The clinical quality construct reflects the degree to which the hospital adheres to quality standards and keeps complication and re-hospitalization rates low.

The meaning of the term organizational performance or institutional success in the hospital sector has been discussed intensely (Fottler, 1987; McCracken et al., 2001). Like any other business, hospitals have to think and act economically and be able to both fund themselves and remain financially solvent-especially given the increasingly limited availability of public funding. As discussed by Chan and Seaman (2009) in their empirical study, patient satisfaction may even have a higher meaning for hospital performance evaluation than economic outcomes. In this study both dimensions are employed for assessing hospital performance: The financial performance construct reflects the degree to which a hospital is 
able to generate revenues to finance future investments, keep process costs low and the overall cost level competitive, whereas the patient satisfaction construct reflects the degree to which a hospital's patients feel adequately treated and informed, value the smooth procedures and do not issue complaints. An overview over the constructs used in this study is provided in Table 1.

Table 1. Construct definitions

\begin{tabular}{ll}
\hline Construct & Definition \\
\hline Process orientation (PO) & The PO construct reflects the degree to which the staff of a hospital \\
& thinks and works truly flow-oriented across all clinical and support \\
& functions and is committed to continuous improvement. \\
& The W construct reflects the degree to which a hospital's entire workforce \\
Workforce conditions (W) & is competent and shows a high employee satisfaction. \\
Operational efficiency (OE) & The OE construct reflects the degree to which a hospital works both \\
& fluently and steadily and is capable of realizing short waiting times and \\
Clinical quality (CQ) & lengths of stay. \\
The CQ construct reflects the degree to which the hospital adheres to \\
quality standards and keeps complication and re-hospitalization rates low. \\
The PS construct reflects the degree to which a hospital's patients feel \\
adequately treated and informed, value the smooth procedures and do not \\
issue complaints. \\
The FP construct reflects the degree to which a hospital is able to \\
generate revenues to finance future investments, keep process costs low \\
and the overall cost level competitive
\end{tabular}

Based on the conceptualization of the relevant constructs, we now deduce hypothesized relationships. A proposition that has consistently been made by various researchers is that process orientation has a strong impact on the efficiency of operations (Gemmel et al., 2008; Sussan and Johnson, 2003). It was found that " $25 \%$ of the variation in hospital efficiency is accounted for by the degree of process-based organization" (Vera and Kuntz, 2007). They conclude that hospital efficiency largely depends on the degree to which the hospital works process-oriented. Following these findings, the first hypothesis of this study reads: 
Hypothesis 1a: Process orientation is expected to have a positive effect on operational efficiency.

According to West (2001) there might also exist a link between process orientation and the workforce. As Poelmans et al. (2010) remark, clear process definitions (e.g. of clinical pathways) "facilitate communication between healthcare professionals". It can be expected that process orientations contributes to more ambitious and satisfied employees, leading to the following hypothesis:

Hypothesis 1b: Process orientation is expected to have a positive effect on workforce conditions.

In their study of two orthopedic units in Scotland, Bragato and Jacobs (2003) find that the introduction of clinical pathways significantly contributed to a reduction of variation in processes and in the overall outcome of care. Both Harden and Resar (2004) and Marley et al. (2004) support this finding, observing in their respective studies that a continuous assessment and improvement of hospital processes enhances clinical outcomes and patient safety and reduces unplanned readmissions. Based on these findings the next hypothesis is: Hypothesis 1c: Process orientation is expected to have a positive effect on clinical quality.

Workforce conditions take the central position in the proposed research model. A number of researchers have investigated the influence of a hospital's personnel on health services quality resulting, however, in ambiguous findings. In a comprehensive literature review by West (2001), studies were analyzed that reported a weak influence of personnel experience and competencies on the quality of care. Contrary to these findings are the results presented by Yang and Tung (2006), who found a significant reduction of the net mortality 
rate as a consequence of increased personnel training. As a result, the following two relationships are hypothesized:

Hypothesis 2a: Workforce conditions are expected to have a positive effect on operational efficiency.

Hypothesis 2b: Workforce conditions are expected to have a positive effect on clinical quality.

DC theory suggests that an organization needs to excel on "multiple strategically important vectors" in order to achieve superior performance (Ma, 1998). Building on this proposition, the research model is designed as a two-layer feed-forward system connecting each competitive advantage construct with each performance construct. The validity of this assumption is further supported by prior research. Analyzing hospitals in Taiwan, Yang and Tung (2006) found that shorter lengths of necessary stay lead to a significantly better operating profit margin. Another study by Chang et al. (2008) observed an increase in patient satisfaction when interdepartmental admission times and overall delays were reduced. These research findings support the expectation that operational efficiency may improve both financial performance and patient satisfaction. Thus, the following hypothesis is suggested:

Hypothesis 3a: Operational efficiency is expected to have a positive effect on financial performance.

Hypothesis 3b: Operational efficiency is expected to have a positive effect on patient satisfaction.

It is expected that the quality and satisfaction of hospital personnel have a positive effect in particular on the satisfaction level of patients and to an unknown extent also on financial performance. The study at hand assumes a positive effect of workforce conditions in both financial performance and patient satisfaction, and proposes: 
Hypothesis 4a: Workforce conditions are expected to have a positive effect on financial performance.

Hypothesis 4b: Workforce conditions are expected to have a positive effect on patient satisfaction.

The effects of clinical quality on financial performance and patient satisfaction are two of the most intensively discussed relationships in hospital performance research. A study by Lovaglio (2011) found that clinical quality is a strong predictor of patient satisfaction. Performing their analysis on specific key performance indicators Yang and Tung (2006) found that a higher return on assets, which in their study represents the financial BSC perspective, was significantly determined by a lower net mortality, which in their study represents the organizational learning and growth perspective. Consistent with a rich body of prior research it is thus hypothesized that clinical quality contributes positively to financial performance patient satisfaction:
Hypothesis 5a: Clinical quality is expected to have a positive effect on financial performance.
Hypothesis 5b: Clinical quality is expected to have a positive effect on patient satisfaction.

\subsection{Study context}

This study mainly reflects the realities of the Swiss healthcare sector, and in particular the situation of Swiss general hospitals. The Swiss hospital landscape is characterized by the existence of both, public organizations owned and subsidized by local and regional authorities, and private-owned organizations which operate under for-profit models. According to the statistics of the OECD (2013), hospital density is comparatively high with 4.87 beds per 1000 inhabitants as compared to 3.05 in the US or 2.95 in the UK. 
Permanent residents of Switzerland are required to purchase a health insurance from one of the 66 private health insurance companies in the country (Swiss Federal Office of Public Health, 2015). This obligatory insurance covers the majority of standard procedures and illness (accidents are covered by a separate insurance plan), while maintaining the freedom to choose the health service provider one deems most suitable. Additional insurance needs, such as dentistry, non-traditional medical therapies etc., can be covered by a supplementary health insurance.

Since 2012, hospital inpatient services are funded by a case-based remuneration scheme, named Swiss DRG (Diagnosis Related Group). In essence, this means that hospitals are reimbursed by the health insurance companies depending on the patient's diagnosis. Through this reimbursement, running costs and long-term infrastructure investments have to be financed-regardless of any actual costs of the hospital for delivering the service. Since financial performance and patient satisfaction critically affect the remuneration and longterm viability of a hospital, our study particularly concentrates on these two aspects of performance as opposed to other prior research that rather focused on innovation effectiveness (Piening, 2011) or employee satisfaction (Harmon et al., 2003). We believe that our study is interesting for other contexts, where there is the same chance that the effects of process orientation could be diverted from improving the patients' satisfaction in favor of a hospital's financial performance.

\subsection{Survey procedure $\&$ data collection}

Our data collection strategy involved a quantitative survey and semi-structured pre- and post survey interviews for testing and validating the instrument and findings. We followed a multi-stage sampling procedure for selecting our study participants. We started with a stratified theoretic sampling on organizational level in order to split the population into representative subgroups (or strata) such that each hospital belongs to a single stratum. In 
Switzerland, the population of hospitals is comprehensively portrayed in biennial reports from the Swiss Federal Statistical Office (2014). Around 69 percent of the hospitals are public, while the rest of 31 percent are private. We only focused on general hospitals rather than specialized ones (e.g. psychiatric clinics, rehabilitation clinics, nursing homes), which may be operated under quite different financial agreements and conditions compared to general hospitals. In the second stage, we used random sampling for selecting our study participants in order to capture the opinions of a representative population. We sent our questionnaire to 319 administrative hospital managers and clinical directors of general hospitals. The questionnaire consisted of four blocks of questions, including questions related to process orientation, clinical quality, patient satisfaction, and the role of hospital personnel. The draft version of the questionnaire was checked beforehand by leading nursing and medical staff, with a view to removing any inconsistencies and generally improving the structure. Since evidence exists, that social norms have a strong impact on health workers (Walston and Chadwick, 2003), we additionally conducted parallel interviews with "opinion leaders" in order to detect distortions like group behavior or discipline related attitudes and perceptions.

A total of 149 questionnaires had been returned, yielding a response rate of 47 percent. 145 questionnaires were complete and regarded in the subsequent analyses. Respondent's demographics revealed that 50 percent classify their job as managerial, 23 percent as clinical/therapeutic, 12 percent as consulting hospital management, and 15 percent as other.

\section{ANALYSIS \& HYPOTHESES TESTING}

For the purpose of theory development or the extension of existing structural theory, the partial least square (PLS) approach has become a quasi-standard (Hair et al., 2011). PLS evaluates measures and its structural model, which is based on factor analyses and 
regression analyses. It is therefore considered particularly suitable for the objective pursued in this study.

\subsection{Measurement model}

The model proposed in this study consists of four reflective (process orientation, workforce conditions, clinical quality, and patient satisfaction) and two formative measures (operational efficiency and financial performance). Evaluating the reflective measures involves assessing the reliability as well as the convergent and discriminant validity of the scales employed (Chin, 2010). In order to assess indicator reliability, confirmatory factor analysis was used. A factor loading of 0.7 and more indicates that at least 50 percent of the indicator's variance is explained through the latent variable (Götz et al., 2010). As seen from Table 2, all the latent constructs exceed at 0.7 , while PO9 was 0.698 . Therefore, their significance was high, at $\mathrm{P}<0.001$.

Table 2. Reflective measurements

\begin{tabular}{|c|c|c|c|c|c|}
\hline \multicolumn{2}{|c|}{ Constructs and indicators } & $\mathbf{M}$ & SD & Loadings & t-statistic \\
\hline \multicolumn{6}{|c|}{$\begin{array}{l}\text { Process orientation (5-tiered Likert scale; } 1 \text { = "stro } \\
\text { 2009; Vera and Kuntz, 2007; Gemmel et al., 2008) }\end{array}$} \\
\hline PO1 & $\begin{array}{l}\text { The work in our hospital is process- } \\
\text { oriented. }\end{array}$ & 3.39 & 1.09 & 0.777 & $30.134^{* * *}$ \\
\hline PO2 & $\begin{array}{l}\text { Processes are documented and/or } \\
\text { modeled. }\end{array}$ & 3.27 & 1.12 & 0.807 & $26.536^{* * *}$ \\
\hline PO3 & $\begin{array}{l}\text { Processes have defined owners (e.g. case } \\
\text { managers). }\end{array}$ & 3.17 & 1.10 & 0.783 & $21.852^{* * *}$ \\
\hline PO4 & $\begin{array}{l}\text { Process owners (e.g. case managers) are } \\
\text { authorized to issue directives. }\end{array}$ & 2.88 & 1.12 & 0.742 & $16.446^{* * *}$ \\
\hline PO5 & $\begin{array}{l}\text { The performance of all processes is } \\
\text { reviewed on a regular basis. }\end{array}$ & 2.81 & 1.18 & 0.842 & $31.469^{* * *}$ \\
\hline PO6 & $\begin{array}{l}\text { The results of performance measurement } \\
\text { are used to change processes. }\end{array}$ & 3.15 & 1.12 & 0.791 & $22.968^{* * *}$ \\
\hline PO7 & Unsatisfactory processes are adapted. & 3.48 & 0.93 & 0.821 & $29.995^{* * *}$ \\
\hline PO8 & $\begin{array}{l}\text { We have a defined procedure in place for } \\
\text { changing processes. }\end{array}$ & 2.79 & 1.28 & 0.701 & $13.998^{* * *}$ \\
\hline
\end{tabular}


processes is encouraged through regular

training.

Workforce conditions (5-tiered Likert scale; 1 = "strongly disagree", 5 = "strongly agree") based on (Kershaw and Kershaw, 2001; Olden and Smith, 2008; Walker and Dunn, 2006)

\begin{tabular}{llcccc}
\hline W1 & Our hospital has low turnover rate of 3.83 & 0.96 & 0.730 & $14.783^{* * *}$ \\
& staffs. \\
W2 & Our employee satisfaction is high. & 3.43 & 1.03 & 0.885 & $48.804^{* * *}$ \\
W3 & Our hospital is known for high 4.08 & 0.93 & 0.837 & $31.247^{* * *}$ \\
& competency of staffs (good reputation).
\end{tabular}

Clinical quality (5-tiered Likert scale; 1 = "strongly disagree", 5 = "strongly agree") based on (Griffith et al., 2006; Olden and Smith, 2008; Zelman et al., 2003)

\begin{tabular}{|c|c|c|c|c|c|}
\hline CQ1 & $\begin{array}{l}\text { Our hospital has hardly any redundant } \\
\text { activities (e.g. redundant examinations). }\end{array}$ & 3.79 & 0.91 & 0.754 & $18.360^{* * *}$ \\
\hline CQ2 & $\begin{array}{l}\text { We have a low complication rate in our } \\
\text { processes. }\end{array}$ & 3.28 & 1.05 & 0.848 & $31.712^{* * *}$ \\
\hline CQ3 & $\begin{array}{l}\text { Processes in our hospital meet the } \\
\text { hospital's defined quality standards. }\end{array}$ & 3.26 & 0.88 & 0.881 & $47.916^{* * *}$ \\
\hline CQ4 & $\begin{array}{l}\text { Our hospital has a low re-hospitalization } \\
\text { rate. }\end{array}$ & 3.90 & 0.85 & 0.724 & $13.400^{* * *}$ \\
\hline \multicolumn{6}{|c|}{$\begin{array}{l}\text { Patient satisfaction (5-tiered Likert scale; } 1=\text { "strongly disagree", } 5=\text { "strongly agree") based on (Griffith et al., } \\
\text { 2002; Gumbus et al., 2003; Walker and Dunn, 2006) }\end{array}$} \\
\hline PS1 & $\begin{array}{l}\text { Our patients feel sufficiently informed } \\
\text { about their treatment process. }\end{array}$ & 3.61 & 0.86 & 0.776 & $16.515^{* * *}$ \\
\hline PS2 & $\begin{array}{l}\text { Our patients feel adequately cared for and } \\
\text { advised. }\end{array}$ & 3.90 & 0.84 & 0.905 & $51.717^{* * *}$ \\
\hline PS3 & $\begin{array}{l}\text { Our patients appreciate smooth processes } \\
\text { and short waiting times in our hospital. }\end{array}$ & 3.62 & 1.11 & 0.798 & $20.821^{* * *}$ \\
\hline PS4 & $\begin{array}{l}\text { Our hospital has a small number of } \\
\text { patient complaints. }\end{array}$ & 3.83 & 0.94 & 0.831 & $29.780^{* * *}$ \\
\hline
\end{tabular}

Notes: Significance: ${ }^{* * *} \mathrm{p}<0.001 ;{ }^{* *} \mathrm{p}<0.01 ;{ }^{*} \mathrm{p}<0.05 ;{ }^{\text {n.s. }} \mathrm{p}>0.05$; two-tailed test applied

Statistics for measuring internal consistency of reflective constructs are Cronbach's alpha and composite reliability $\rho$ (Chin, 2010). A construct is considered internally consistent if its Cronbach's alpha and its $\rho$ both exceed a value of 0.7 (Tenenhaus et al., 2005). Cronbach's alpha and composite reliability values of all constructs surpassed the required thresholds, with the lowest values being 0.756 and 0.859 respectively. Convergent validity 
examines the ability of a latent variable to explain its indicators' variance (Henseler et al., 2009). The average variance extracted (AVE) captures the amount of explained variance relative to the total amount of variance and is considered sufficient if it exceeds a value of 0.5 "meaning that 50 percent or more variance of the indicators should be accounted for" (Chin, 2010). The lowest AVE value measured in this study was 0.601. Discriminant validity measures if the latent constructs used are in fact conceptually distinct. As suggested by Fornell and Larcker (1981) discriminant validity is provided for when the square root of AVE of each construct exceeds the correlation of this construct with any other of the model's constructs. The highest bipartite correlation (0.724) in this study was found between workforce conditions and patient satisfaction. Considering the lowest square root of AVE being 0.775 for process orientation, the previous criterion is thus also met. A summary of the quality criteria employed is provided in Table 3.

Table 3. Assessment of internal consistency, convergent validity, and discriminant validity

\begin{tabular}{llllllll}
\hline Construct & Cron- & $\rho$ & AVE & \multicolumn{4}{l}{ Inter-construct correlations } \\
\cline { 5 - 7 } & bach's $\alpha$ & & & PO & W & CQ & PS \\
\hline Process orientation (PO) & 0.917 & 0.931 & 0.601 & $\mathbf{0 . 7 7 5}$ & & \\
Workforce conditions (W) & 0.756 & 0.859 & 0.672 & 0.512 & $\mathbf{0 . 8 2 0}$ & \\
Clinical quality (CQ) & 0.817 & 0.879 & 0.647 & 0.595 & 0.698 & $\mathbf{0 . 8 0 4}$ & $\mathbf{0 . 8 2 9}$ \\
Patient satisfaction (PS) & 0.847 & 0.897 & 0.687 & 0.483 & 0.724 & 0.719 & $\mathbf{0 . 7 9}$ \\
\hline
\end{tabular}

Notes: Items on diagonal (shaded) represent the square root of the AVE values

Compared to reflective measures, the direction of causality between a latent construct and its indicators is reversed in formative measures. Consequently, alternative tests are required in order to assess their validity and reliability. The construct validity of the formative measures was assessed by examining the item weightings (Jarvis et al., 2003). As can be seen from Table 4, six out of seven items contribute substantially to the formation of the intended construct $(\mathrm{P}<0.001)$. Only one item $(\mathrm{OP} 3)$ is not significant. However, the item is not eliminated as in formative or composite measures "all indicators, as a group, jointly 
determine the conceptual and empirical meaning of the construct" (Jarvis et al., 2003). Eliminating an indicator could thus alter the meaning of the construct. Overall, the results of measurement model assessment exhibited sufficient quality to proceed with testing the proposed structural model.

Table 4. Formative measurements

\begin{tabular}{|c|c|c|c|c|c|c|}
\hline \multicolumn{2}{|c|}{ Constructs and indicators } & $\mathbf{M}$ & SD & Weight & t-statistic & VIF \\
\hline \multicolumn{7}{|c|}{$\begin{array}{l}\text { Operational efficiency (5-tiered Likert scale; } 1=\text { "strongly disagree", } 5=\text { "strongly agree") based on (Chow et al., } \\
\text { 1998; Griffith et al., 2002) }\end{array}$} \\
\hline OP1 & $\begin{array}{l}\text { The processes in our hospital are } \\
\text { efficient. }\end{array}$ & 3.10 & 1.00 & 0.496 & $6.106^{* * *}$ & 1.572 \\
\hline OP2 & $\begin{array}{l}\text { Our hospital has short waiting } \\
\text { times. }\end{array}$ & 3.22 & 1.17 & 0.452 & $5.982^{* * *}$ & 1.515 \\
\hline OP3 & $\begin{array}{l}\text { Our hospital has a short length of } \\
\text { stay. }\end{array}$ & 3.69 & 1.05 & -0.026 & $0.227^{\text {n.s. }}$ & 2.617 \\
\hline OP4 & $\begin{array}{l}\text { We discharge our patients within } \\
\text { the average length of stay. }\end{array}$ & 3.84 & 0.95 & 0.348 & $3.820^{* * *}$ & 2.171 \\
\hline \multicolumn{7}{|c|}{$\begin{array}{l}\text { Financial performance (5-tiered Likert scale; } 1=\text { "strongly disagree", } 5=\text { "strongly agree") based on (Lovaglio, } \\
\text { 2011; Meyer and Collier, 2001) }\end{array}$} \\
\hline FP1 & $\begin{array}{l}\text { Our hospital is generating the } \\
\text { desired growth in revenues. }\end{array}$ & 3.64 & 1.17 & 0.332 & $3.256^{* *}$ & 1.533 \\
\hline FP2 & Our process costs are low. & 3.36 & 1.18 & 0.416 & $4.347^{* * *}$ & 1.801 \\
\hline FP3 & $\begin{array}{l}\text { Our costs are competitive } \\
\text { (market-oriented). }\end{array}$ & 2.89 & 1.07 & 0.431 & $4.380^{* * *}$ & 1.981 \\
\hline
\end{tabular}

Notes: Significance: ${ }^{* * *} \mathrm{p}<0.001 ;{ }^{* *} \mathrm{p}<0.01 ;{ }^{*} \mathrm{p}<0.05$; ${ }^{\text {n.s. }} \mathrm{p}>0.05$; two-tailed test applied

\subsection{Structural model}

This research tested the structural model for examining the explanatory power of the hypothesized relationships between the latent constructs. We opted for PLS in order to overcome problematic model identification issues since it is a powerful method for analyzing complex models using smaller samples with few distributional assumptions (Ringle et al., 2012). Following Götz et al. (2010), bootstrapping with 500 samples was performed to assess each path coefficient's significance, which is an adequate 
nonparametric approach (Chin, 2010). The goodness of path coefficients $(\beta)$, the precision of the PLS estimates of our research model, was $62 \%$ for the patient satisfaction and $60 \%$ for the financial performance. The variance $\left(\mathrm{R}^{2}\right)$ of operational efficiency, workforce conditions and clinical quality was $55 \%, 26 \%$ and $56 \%$ respectively, which indicates that the given constructs are explained by our model. Path coefficients, significance levels and $\mathrm{R}^{2}$ values for the proposed structural model are primary evaluation criteria (Hair et al., 2011) and shown in Figure 3.

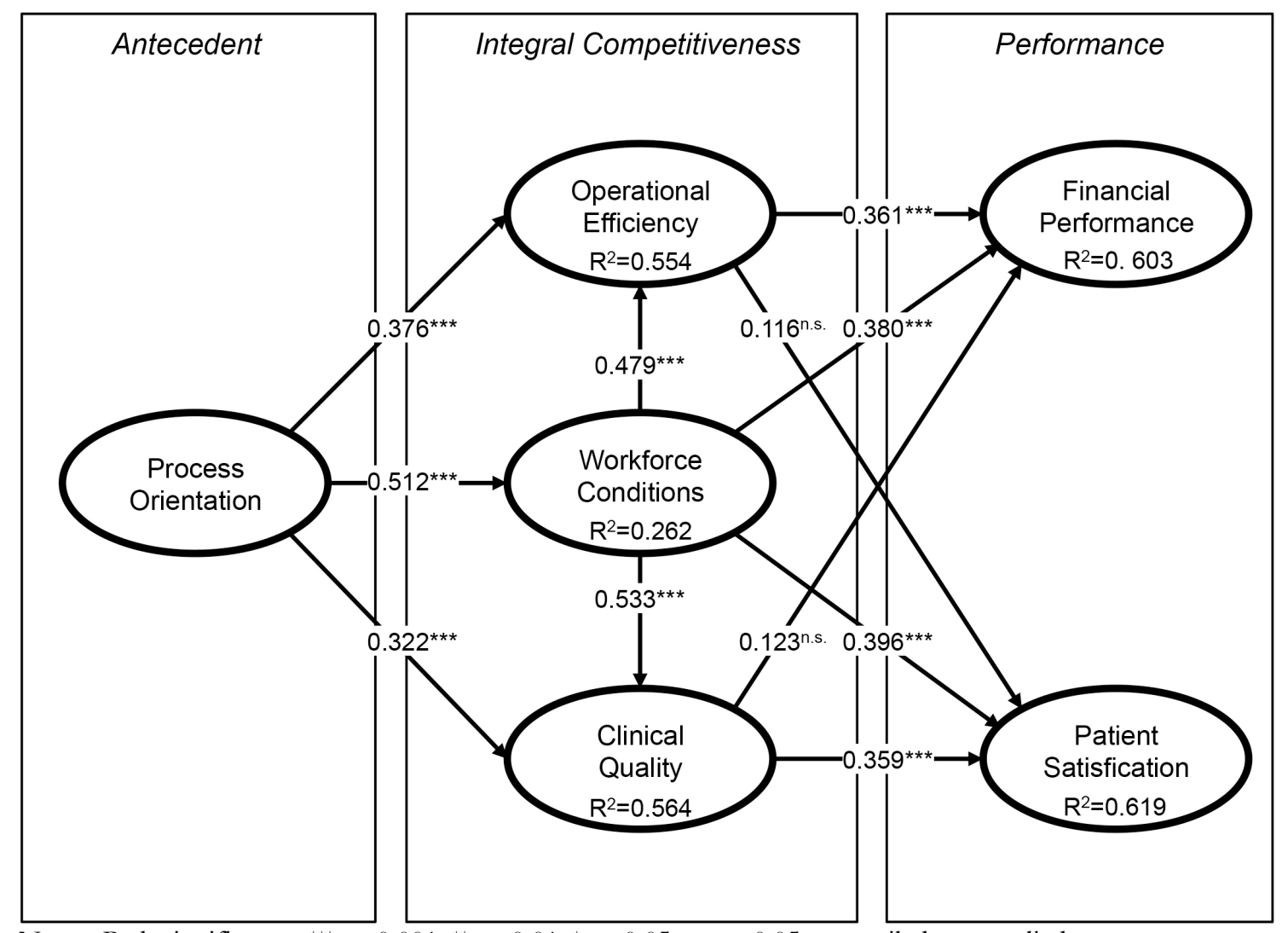

Notes: Path significance: ${ }^{* * *} \mathrm{p}<0.001$; $^{* *} \mathrm{p}<0.01$; $^{*} \mathrm{p}<0.05$; ${ }^{\text {n.s. }} \mathrm{p}>0.05$; two-tailed test applied

Fig. 3. PLS analysis of research model

Examining the eleven hypothesized relationships in the model, two paths were found insignificant and thus did support the hypotheses neither of the link between operational efficiency and patient satisfaction nor of the link between clinical quality and financial performance. 
Out of eleven hypothesized relationships, only two paths were found insignificant. In sum, operational efficiency doesn't show significance to patient satisfaction as well as clinical quality doesn't show significance to financial performance. All other paths were found being significant at $\mathrm{P}<0.001$, meanwhile the directionality of all paths was confirmed as hypothesized in the proposed model. All three constructs constituting a hospital's positional advantage, operational efficiency, workforce conditions and clinical quality were predicted positively by process orientation $(\beta=0.376, \beta=0.512$ and $\beta=0.322$ respectively), providing support for hypothesis $\mathrm{H} 1 \mathrm{a}, \mathrm{H} 1 \mathrm{~b}$ and H1c. These findings confirmed the initial expectation that a hospital's positional advantage is strongly determined by its capability to work process-oriented. Having a work environment where procedures and structures are rather flow-oriented instead of functionally organized seems to be positive in a number of ways: The highly significant linkage between process orientation to workforce conditions suggests that hospital personnel perceived themselves much confident, resulting in low turnover ratio at their hospital, which is a key determinant for attracting capable and motivated personnel and for health professionals to be more productive. Consequently, creating a positive work environment had a strong positive impact on both operational efficiency $(\beta=0.479)$ and clinical quality $(\beta=0.533)$, supporting hypothesis $\mathrm{H} 2 \mathrm{a}$ and H2b. Financial performance was positively predicted by two out of three determinants, in this case operational efficiency $(\beta=0.361)$ and workforce conditions $(\beta=0.380)$, which supported $\mathrm{H} 3 \mathrm{a}$ and $\mathrm{H} 4 \mathrm{a}$. The suggested positive effect of clinical quality on financial performance, by contrast, was insignificant-leading to a rejection of hypothesis H5a. A possible reason for the rejection of this hypothesis could have been the fact that the quality of service delivery, as a factor for reimbursing the hospital's performance, is not directly taken into account by a case-based remuneration scheme, such as SwissDRG. On the contrary, poor clinical quality often causes complications by patients, whose treatment can be billed additionally. In this sense, our results may reflect a national idiosyncrasy and thus 
need to be considered with caution, particularly in health systems that do not follow casebased remuneration of their hospitals.

Finally, patient satisfaction as the second construct measuring hospital performance was predicted positively by two of the three proposed determinants of hospital performance, namely hospital workforce conditions $(\beta=0.396)$ and clinical quality $(\beta=0.359)$, lending support for hypotheses $\mathrm{H} 4 \mathrm{~b}$ and $\mathrm{H} 5 \mathrm{~b}$, but not by the third determinant, operational efficiency, thereby refuting hypothesis H3b. A reason for the rejection of this hypothesis could have been the circumstance that operational services, as opposed to clinical services, are often performed in the background without the noticing of patients. Hence, patients might not recognize the effects of an improvement in this area directly. Another, more practical reason, could have been the fact that patients satisfaction was elicited from a managerial assessment and not from patients. Most of our respondents were hospital managers or clinical directors, and hardly any professionals working in a supportive role. We believe that certainly the personal world-view on the significance of organizational and clinical services regarding the hospital's performance clearly has an impact on the reported findings, which are summarized in the subsequent Table 5.

Table 5. Results of PLS path analysis

\begin{tabular}{llll}
\hline Hypothesis & Path description & Significance & Result \\
\hline $\mathrm{H} 1 \mathrm{a}$ & Process orientation $\rightarrow$ Operational efficiency & $0.376^{* * *}$ & Supported \\
$\mathrm{H} 1 \mathrm{~b}$ & Process orientation $\rightarrow$ Workforce conditions & $0.512^{* * *}$ & Supported \\
$\mathrm{H} 1 \mathrm{c}$ & Process orientation $\rightarrow$ Clinical quality & $0.322^{* * *}$ & Supported \\
$\mathrm{H} 2 \mathrm{a}$ & Workforce conditions $\rightarrow$ Operational efficiency & $0.479^{* * *}$ & Supported \\
$\mathrm{H} 2 \mathrm{~b}$ & Workforce conditions $\rightarrow$ Clinical quality & $0.533^{* * *}$ & Supported \\
$\mathrm{H} 3 \mathrm{a}$ & Operational efficiency $\rightarrow$ Financial performance & $0.361^{* * *}$ & Supported \\
$\mathrm{H} 3 \mathrm{~b}$ & Operational efficiency $\rightarrow$ Patient satisfaction & $0.116^{\text {n.s. }}$ & Not supported \\
$\mathrm{H} 4 \mathrm{a}$ & Workforce conditions $\rightarrow$ Financial performance & $0.380^{* * *}$ & Supported
\end{tabular}




$\begin{array}{llll}\mathrm{H} 4 \mathrm{~b} & \text { Workforce conditions } \rightarrow \text { Patient satisfaction } & 0.396^{* * *} & \text { Supported } \\ \mathrm{H} 5 \mathrm{a} & \text { Clinical quality } \rightarrow \text { Financial performance } & 0.123^{\text {n.s. }} & \text { Not supported } \\ \mathrm{H} 5 \mathrm{~b} & \text { Clinical quality } \rightarrow \text { Patient satisfaction } & 0.359^{* * *} & \text { Supported }\end{array}$

Notes: Path significance: ${ }^{* * *} \mathrm{p}<0.001 ;{ }^{* *} \mathrm{p}<0.01 ;{ }^{*} \mathrm{p}<0.05 ;$ n.s. $\mathrm{p}>0.05$; two-tailed test applied

\section{DISCUSSION AND IMPLICATIONS}

Our study sought to address the research question of how process orientation influenced the hospitals' integral competiveness and performance. In this section, we elaborate on the significance of our findings in three different areas. First, we discuss how our work extends and is related to existing research. Second, we describe the managerial implications that can be derived from our findings. Third, we indicate the most crucial limitations of this study in order for the reader to make the right interpretation of our results.

\subsection{Implications for research}

Albeit process orientation and business process management were said to be highly effective in explaining varying aspects of hospital performance, there is only sparse evidence available. Prior research, such as an early study by Fottler (1987) exploring the effects of process orientation on clinical quality or more recent studies by Gemmel et al. (2008) and Vera and Kuntz (2007) on the effects of process orientation on hospital efficiency, frequently is restricted to analyzing the impact of process orientation with a view to one particular performance dimension.

We found that process orientation is a significant antecedent for both, an increase of integral competitiveness and performance improvements. Similar to the findings reported by Harmon et al. (2003), our study supports the claim that process orientation is highly dependent on the hospital workforce in order that financial performance can be attained. We thus agree with the claim that a much stronger dedication is needed from the hospital workforce when it comes to the collaboration across functional boundaries. Our results 
are, however, different from the mentioned study, since we do not only presuppose a stronger involvement of employees but also a higher level of competency, technology innovation, and low labor turnover such that process orientation really can unfold its full potential.

In line with Piening (2011), we implicitly assume that organizational together with technological innovation plays an important role in the required enhancement of organizational capabilities and learning. Retaining an open-ended and positive view about how hospital professionals embrace new ways of working, thus contradicting previous research that showed that hospital employees stymie the diffusion of innovation (Bhattacherjee and Hikmet, 2007), our study provides evidence that innovation in process orientation may actually help hospital professionals to be more efficient and deliver better quality of care, which according to our findings ultimately also decreases their pressure of work and increases their satisfaction at the workplace.

Our study therefore supports the claim that hospitals indeed can "profit from innovation" (Teece, 2006). We show that benefits from process orientation are multifaceted and accrues different stakeholders, such as hospital workforce, management, and patients. We believe that this is an interesting contribution to existing studies, as we not only reveal the importance of process orientation for efficiency gains, but also for a higher level of clinical quality, personnel and patient satisfaction, and lastly financial performance of the hospital. In this sense, process orientation is a powerful "way of thinking and acting" in order to achieve multiple organizational goals.

\subsection{Managerial implications}

The results of our study allow us to draw the following managerial implications: First, our study showed that process orientation affect healthcare service providers and health service beneficiaries together, which are pertinent to quality of care and patient 
satisfaction. Although many studies give the impression that the introduction of processes is a purely technical matter, we believe that together with the clarification of new roles, clear allocation of tasks, designation of prompt and complete information flows it is also important to provide a rationale to hospital workforce why it eventually makes sense to change well-rehearsed work patterns in favor of more coordinated, cross-functional collaboration or even fully digital processes. In the end, the introduction of process orientation in a hospital represents a major change endeavor, which should not only be well planned in terms of the deployment of technical systems, but also regarding changes in the power structure of the distinct clinical departments and professional roles. We believe that our study provides hospital managers with important managerial implication, which remain unheard: hospitals' process orientation increases quality of care and patient satisfaction. In order to make this happen, hospitals need to invest time and money into novel technologies and transformation management capabilities of people. Although not explicitly reported in this study, this has been a major impulse for many employees of the surveyed hospitals to re-think their daily work routines.

Second, the findings indicate that process orientation induces an enhancement of operational efficiency, which ultimately leads to increased financial performance. Rooted in the logic of the Swiss case-based remuneration scheme, we define simple, yet significant performance indicators for measuring growth and cost efficiency resulting from process orientation. However, in order to fully comprehend the impact of process orientation, more detailed and combined indicators from financial reporting and medical controlling have to be defined and made available (Rohner, 2012). However, one should not make the mistake to concentrate on monitoring and controlling efficiency gains only. As we outlined earlier, process initiatives also considerably improve quality of care, which should be acknowledged and weighted equally important by hospital management. 
Third, in post-survey interviews, many of the respondents expressed concerns related to the perceived phenomenon of "industrializing" the healthcare sector. While they consider it is profitable in the short run, they regard an efficient "factory-like" treatment of patients as counterproductive for the future, because it is likely that unsatisfied patients may choose another hospital for their continued treatment. Since hospital density is high in Switzerland, patients may face little switching costs and quickly turn to another health service provider. Although this might only apply for the context of this study (i.e. high hospital density, short distances, similar quality of service delivery), we suggest monitoring readmissions closely and analyzing patient complaints systematically in order to proactively detect any possible trade-offs that could emerge.

\subsection{Limitations of our study and suggestions for future research}

As with any empirical study, this work has limitations. When interpreting the findings presented in this study, the reader should take the following limitations into account.

First, the measurement of performance as operationalized in this study completely relies on the personal appraisal of those who completed the survey. While subjective measurement of performance is both valid and common in management research, there is a chance of biased results. Future research may thus also incorporate objective performance measures to further reduce potential bias.

Second, this study purposefully focused on process orientation as the only antecedent of the hospitals' integral competitiveness and organizational performance. But process orientation is not the only competitiveness hospitals may acquire to remain sustainable and/or create a competitive advantage (Janssen and Moors, 2013). Future research on other antecedents is strongly encouraged.

Third, most of the constructs employed in this study have been developed newly. When developing new scales, one of the most important considerations concerns the relationship 
between constructs and items. Regarding the constructs operational efficiency and financial performance, we followed recent calls for a formative operationalization (Petter et al., 2007). The other constructs are operationalized reflectively.

Fourth, though based on a broadly accepted theory, largely supported by existing literature and empirically validated on a data set of 145 , the suggested relationships are still no general truth and should be interpreted with care.

Finally, we acknowledge the inherent limitation of a cross-sectional study design, which prevented us from exploring shifts in performance and integral competitiveness over time. Future research could extend and calibrate our instrument design by including investigating temporal and geographical differences such that evidence is accumulated beyond the contextual limitations of the Swiss healthcare sector.

\section{References}

Albertsen, O.A., Lueg, R. 2014. The balanced scorecard's missing link to compensation, J. Account. \& Organ. Chang., 10(4), 431-465.

Axelsson, R., Axelsson, S.B., Gustafsson, J., Seemann, J. 2014. Organizing integrated care in a university hospital: application of a conceptual framework, Int. J. Integr. Care, 14 (eCollection), e019.

Bhattacherjee, A., Hikmet, N. 2007. Physicians' resistance toward healthcare information technology: a theoretical model and empirical test, Eur. J. Inf. Syst., 16(6), 725-737.

Boudreau, M.-C., Gefen, D., Straub, D.W. 2001. Validation in information systems research: a state-of-the-art assessment, MIS Q., 25(1), 1-16.

Bragato, L., Jacobs, K. 2003. Care pathways: the road to better health services?, J. Health Org. Manage., 17(3), 164-180.

Carter, N., Klein, R., Day, P. 1995. How Organisations Measure Success: The Use of Performance Indicators in Government, Routledge, London.

Chan, Y.-C.L., Seaman, A. 2009. Strategy, structure, performance management, and organizational outcome: application of the balanced scorecard in canadian health care organizations, in: Epstein, M. J., Lee, J. Y. (Eds.), Advances in Management Accounting Emerald Group Publishing Limited, Bingley, pp.151-180. 
Chang, W.-C., Tung, Y.-C., Huang, C.-H., Yang, M.-C.-. 2008. Performance improvement after implementing the balanced scorecard: a large hospital's experience in Taiwan, Total Qual. Manage. \& Bus. Excell., 19(11), 1143-1154.

Chen, H., Tian, Y., Daugherty, P.J. 2009. Measuring process orientation, Int. J. Logist. Manage., 20(2), 213-227.

Chin, W.W. 2010. How to write up and report PLS analyses, in: Vinzi, V.E., Chin, W.W., Henseler, J., Wang, H. (Eds.), Handbook of partial least squares. Concepts, methods and applications, , Springer, Berlin, Heidelberg, pp. 655-690.

Chow, W.C., Ganulin, D., Haddad, K., Williamson, J. 1998. The balanced scorecard: a potent tool for energizing and focusing healthcare organization management, J. Healthc. Manage., 43(3), 263-280.

Churchill, G.A. 1979. A paradigm for developing better measures of marketing constructs, J. of Mark. Res. 16(1), 64-73.

Cleven, A., Winter, R., Wortmann, F., Mettler, T. 2014. Process management in hospitals: an empirically grounded maturity model, Bus. Res., 7(2), 191-216.

Donahue, J.D., Zeckhauser, R.J. 2011. Collaborative governance: Private roles for public goals in turbulent times, Princeton University Press, Princeton, NJ.

Fischman, D. 2010. Applying lean six sigma methodologies to improve efficiency, timeliness of care, and quality of care in an internal medicine residency clinic, Qual. Manage. Health Care, 19(3), 201-210.

Flynn, N. 1997. Public Sector Management, 3 ed., Prentice-Hall, London.

Fornell, C., Larcker, D.F. 1981. Evaluating structural equition models with unobservable variables and measurement error, J. Mark. Res., 18(1), 39-50.

Fottler, M.D. 1987. Health care organizational performance: present and future research, J. Manage., 13(2), 367-391.

Gemmel, P., Vandaelea, D., Tambeurc, W. 2008. Hospital process orientation (HPO): the development of a measurement tool, Total Qual. Manage. \& Bus. Excell., 19(12), 12071217.

Goldstein, S.M., Schweikhart, S.B. 2002. Empirical support for the Baldrige award framework in U.S. hospitals, Health Care Manage. Rev., 27(1), 62-75.

Götz, O., Liehr-Gobbers, K., Krafft, M. 2010. Evaluation of structural equation models using the partial least squares (PLS) approach, in: Vinzi, V.E., Chin, W.W., Henseler, J., Wang, H. (Eds.), Handbook of partial least squares. Concepts, methods and applications, Springer, Berlin, Heidelberg, pp. 691-711. 
Griffith, J.R., Alexander, J.A., Jelinek, R.C., Foster, D.A., Mecklenburg, G.A. 2006. Is anybody managing the store? National trends in hospital performance, J. Healthc. Manage., 51(6), 392-405.

Griffith, J.R., Alexander, J.A., Warden, G.L. 2002. Measuring comparative hospital performance, J. Healthc. Manage., 47(1), 41-57.

Gumbus, A., Belthouse, D.E., Lyons, B. 2003. A three year journey to organizational and financial health using the balanced scorecard: a case study at a Yale New Haven health system hospital, J. Bus. \& Econ. Stud., 9(2), 54-64.

Hair, J.F., Black, W.C., Babin, B.J., Anderson, R.E., Tatham, R.L. 2006. Multivariate data analysis, Pearson, Upper Saddle River, NJ.

Hair, J.F., Ringle, C.M., Sarstedt, M. 2011. PLS-SEM: indeed a silver bullet, J. Mark. Theor. \& Practic., 19(2), 139-151.

Harden, C., Resar, R. 2004. Patient flow in hospitals: understanding and controlling it better, Front. Health Serv. Manage., 20(4), 3-15.

Harmon, J., Scotti, D.J., Behson, S., Farias, G., Petzel, R., Neuman, J.H., Keashly, L. 2003. Effects of high-involvement work systems on employee satisfaction and service costs in veterans healthcare, J. Healthc. Manage., 48(6), 393-406.

Henseler, J., Ringle, C.M., Sinkovics, R.R. 2009. The use of partial least squares path modeling in international marketing, in: Sinkovics, R. R., Ghauri, P. N. (Eds.), New Challenges to International Marketing, Emerald Group Publishing Limited, Bingley, pp. 277-319.

Hung, R.Y.-Y. 2006. Business process management as competitive advantage: a review and empirical study, Total Qual. Manage. \& Bus.Excell., 17(1), 21-40.

Hurst, K. 1996. The managerial and clinical implications of patient-focused care, J. Health Organ. Manage., 10(3), 59-77.

Janssen, M., Moors, E.H.M. 2013. Caring for healthcare entrepreneurs - towards successful entrepreneurial strategies for sustainable innovations in Dutch healthcare, Technol. Forecast. Soc. Chang., 80(7), 1360-1374.

Jarvis, C.B., Mackenzie, S.B., Podsakoff, P.M. 2003. A critical review of construct indicators and measurement model misspecification in marketing and consumer research, J. Consum. Res., 30(2), 199-218.

Kaplan, R.S., Norton, D.P. 1992. The balanced scorecard - measures that drive performance, Harv. Bus. Rev., 70(1), 71-79.

Kershaw, R., Kershaw, S. 2001. Developing a balanced scorecard to implement strategy at St. Elsewhere hospital, Manage. Account. Q., 2(2), 28-35. 
Kim, Y.-M. 2009. Validation of psychometric research instruments: The case of information science, J. Am. Soc. Inf. Sci. \& Technol., 60(6), 1178-1191.

Kohlbacher, M. 2010. The effects of process orientation: a literature review, Bus. Process Manage. J., 16(1), 135-152.

Leggat, S.G., Bartram, T., Stanton, P., Bamber, G.J., Sohal, A.S. 2015. Have process redesign methods, such as Lean, been successful in changing care delivery in hospitals? A systematic review, Pub. Money \& Manage., 35(2), 161-168.

Lovaglio, P.G. 2011. Model building and estimation strategies for implementing the balanced scorecard in health sector, Qual. \& Quant., 45(1), 199-212.

Ma, H. 1998. Creation and preemption for competitive advantage, Manage Decis., 37(3), $259-267$.

Marley, K.A., Collier, D.A., Meyer Goldstein, S. 2004. The role of clinical and process quality in achieving patient satisfaction in hospitals, Decis. Sci., 35(3), 349-369.

McCormack, K. 2001. Business process orientation: do you have it?, Qual. Prog., 34(1), 5158.

McCracken, M.J., Mcilwain, T.F., Fottler, M.D. 2001. Measuring organizational performance in the hospital industry: an exploratory comparison of objective and subjective methods, Health Serv.s Manage. Res., 14(4), 211-219.

Melchert, F., Winter, R., Klesse, M. 2004. Aligning process automation and business intelligence to support corporate performance management, Proceedings of the Americas Conference on Information Systems, New York, pp. 4053-4063.

Mettler, T., Rohner, P. 2009a. An analysis of the factors influencing networkability in the health-care sector, Health Serv. Manage. Res., 22(4), 163-169.

Mettler, T., Rohner, P. 2009b. Performance management in health care: the past, the present, and the future, in: Proceedings of the 9th International Conference on Business Informatics, Vienna, Austria: pp. 699-708.

Mettler, T., Vimarlund, V. 2009. Understanding business intelligence in the context of healthcare, Health Inform. J., 15(3), 254-264.

Meyer, S.M., Collier, D.A. 2001. An empirical test of the causal relationships in the Baldrige Health Care Pilot Criteria, J. Oper. Manage., 19(4), 403-426.

Mutale, W., Stringer, J., Chintu, N., Chilengi, R., Mwanamwenge, M.T., Kasese, N., Balabanova, D., Spicer, N., Lewis, J., Ayles, H. 2014. Application of balanced scorecard in the evaluation of a complex health system intervention: 12 months post intervention findings from the BHOMA intervention: A cluster randomised trial in Zambia, PLoS ONE, 9(4), e93977. 
Nørreklit, H. 2003. The balanced scorecard: what is the score? A rhetorical analysis of the balanced scorecard, Account. Organ. \& Soc., 28(6), 591-619.

OECD. 2013. Hospital beds per 1000 population. Retrieved May 11, 2016, from http://www.oecd-ilibrary.org/sites/health_glance-2013en/04/03/index.html?itemId=/content/chapter/health_glance-2013-34en\&mime'Type $=$ text $/ \mathrm{html}$

Olden, P.C., Smith, C.M. 2008. Hospitals, community health, and balanced scorecards, Acad. Health Care Manage. J., 4(1), 39-56.

Pai, F.-Y., Huang, K.-I. 2011. Applying the technology acceptance model to the introduction of healthcare information systems. Technol. Forecast. Soc. Chang., 78(4), 650-660.

Petter, S., Straub, D., Rai, A. 2007. Specifying formative constructs in information systems research, MIS Q., 31(4), 623-656.

Piening, E.P. 2011. Insights into the process dynamics of innovation implementation, Pub. Manage. Rev., 13(1), 127-157.

Pink, G.H., Mckillop, I., Schraa, E.G., Preyra, C., Montgomery, C., Baker, G.R. 2001. Creating a balanced scorecard for a hospital system, J. Health Care Financ., 27(3), 1-21.

Poelmans, J., Dedene, G., Verheyden, G., Van der Mussele, H., Viaene, S., Peters, E. 2010. Combining business process and data discovery techniques for analyzing and improving integrated care pathways, in: Perner, P. (Ed.), Advances in Data Mining. Applications and Theoretical Aspects, Springer, Berlin, Heidelberg, pp. 505-517.

Ringle, CM., Sarstedt, M. Straub, DW. 2012. A critical look at the use of PLS-SEM in MIS Quarterly, MIS Q., 36(1), iii-xiv.

Rohner, P. 2012. Achieving impact with clinical process management in hospitals: An inspiring case, Bus. Process Manage. J., 18(4), 600-624.

Rouse, J. 1999. Performance management, quality management, and contracts, in: Horton, S., Farnham, D. (Eds.), Public Management in Britain, Macmillan, Basingstoke, pp. 76-93. Skrinjar, R., Bosilj-Vuksic, V., Indihar-Stemberger, M. 2008. The impact of business process orientation on financial and non-financial performance, Bus. Process Manage. J., 14(5), 738-754.

Spangenberg, H. 1994. Understanding and Implementing Performance Management, Juta, Plumstead.

Sussan, A.P., Johnson, W.C. 2003. Strategic capabilities of business process: looking for competitive advantage, Compet. Rev., 13(2), 46-52. 
Swiss Federal Office of Public Health. 2015. List of accredited health insurance companies.

$\begin{array}{llll}\text { Retrieved } & \text { May } & \text { 11, 2016, from }\end{array}$ http://www.bag.admin.ch/themen/krankenversicherung/00295/11274/

Swiss Federal Statistical Office. 2014. Hospital Statistics, 532-1403-05, Swiss Federal Statistical Office, Neuchâtel, Switzerland.

Teece, D.J. 2006. Reflections on “profiting from innovation”, Res. Pol., 35(8), 1131-1146.

Tenenhaus, M., Vinzi, V.E., Chatelin, Y.-M., Lauro, C. 2005. PLS path modeling, Comput. Stat. \& Data Anal., 48(1), 159-205.

Veillard, J., Champagne, F., Klazinga, N., Kazandjian, V., Arah, O.A., Guisset, A.-1. 2005. A performance assessment framework for hospitals: the WHO regional office for Europe PATH project, Int. J. Qual. Health Care, 17(6), 487-496.

Vera, A., Kuntz, L. 2007. Process-based organization design and hospital efficiency, Health Care Manage. Rev., 32(1), 55-65.

Walker, K.B., Dunn, L.M. 2006. Improving hospital performance and productivity with the balanced scorecard, Acad. Health Care Manage. J., 2(1), 85-110.

Walston, S., Chadwick, C. 2003. Perceptions and misperceptions of major organizational changes in hospitals: do change efforts fail because of inconsistent organizational perceptions of restructuring and reengineering?, Int. J. Publ. Admin., 26(14), 1581-1605.

West, E. 2001. Management matters: the link between hospital organisation and quality of patient care, Qual. Health Care, 10(1), 40-48.

Wicks, A.M., St Clair, L., Kinney, C.S. 2007. Competing values in healthcare: balancing the (un)balanced scorecard, J. Healthc. Manage., 52(5), 309-324.

Wu, I.-L., Chen, J.-L. 2014. A stage-based diffusion of IT innovation and the BSC performance impact: A moderator of technology-organization-environment, Technol. Forecast. Soc. Chang., 88, 76-90.

Yang, M.-C., Tung, Y.-C. 2006. Using path analysis to examine causal relationships among balanced scorecard performance indicators for general hospitals: the case of a public hospital system in Taiwan, Health Care Manage. Rev., 31(4), 280-288.

Yarmohammadian, M.H., Ebrahimipour, H., Doosty, F. 2014. Improvement of hospital processes through business process management in Qaem teaching hospital: a work in progress, J. Educ. Health Prom., 3(1), 111.

Zairi, M. 1997. Business process management: a boundaryless approach to modern competitiveness, Bus. Process Manage. J., 3(1), 64-80.

Zelman, W.N., Pink, G.H., Matthias, C.B. 2003. Use of the balanced scorecard in health care, J. Health Care Financ., 29(4), 1-16. 


\section{APPENDIX - Instrument design}

The six constructs of interest to this study are process orientation, operational efficiency, workforce conditions, clinical quality, patient satisfaction, and financial performance. The development of the survey instrument was guided by Churchill (1979) well-known and often employed procedure. The process was initiated with a comprehensive literature review encompassing the areas of business process management, performance management and healthcare management in order to establish and specify the domain of each construct. This step yielded in a concise definition for each construct delineating its scope and embedding it in the overall theoretical coherence. In order to both increase the reliability of research results and nurture a cumulative research tradition, it is recommended to use validated scales from preceding studies wherever possible (Boudreau et al., 2001; Kim, 2009). If the subject under investigation does not have a rich history of prior research, the development of new scales is appropriate (Hair et al., 2006). The generation of items to represent each of the six constructs started with a broad search for available scales. The analysis of existing literature revealed that in the healthcare context neither process orientation nor the BSC and its different perspectives have so far been subject of intense quantitative research. Nonetheless, wherever available, existing measures were adapted. For measuring process orientation, the survey instrument developed by Chen et al. (2009) was useful. Its items examine the degree to which an organization conducts its activities through end-to-end processes rather than in separate functional areas (Chen et al., 2009). As the original construct was developed for the electronics industry their wording was modified to fit the healthcare context of this study. Moreover, the scope was extended through additional items so as to account for a hospital's capabilities in diagnosing the necessity for and implementing process change as suggested by prior research (Gemmel et al., 2008; Vera and Kuntz, 2007). The BSC-having been recognized as a potent instrument for guiding hospital performance management (Gumbus et al., 2003; Walker and Dunn, 2006; Zelman et al., 2003)—has hitherto mainly been studied through qualitative research. The generation of items measuring the BSC 
perspectives has thus largely been informed by results from available case study research. Competency, satisfaction and loyalty are commonly cited indicators for measuring the workforce perspective in the hospital context (Kershaw and Kershaw, 2001; Olden and Smith, 2008; Walker and Dunn, 2006). Thus, items representing this study's construct regarding workforce conditions examine the level of employee competency and satisfaction as well as the stability of the employment rate. Operational efficiency is represented through items measuring the extent to which a hospital is capable of realizing short waiting times and minimizing the average length of stay (Chow et al., 1998; Griffith et al., 2002). The importance of assessing clinical quality for measuring hospital performance has been emphasized by prior researchers (Olden and Smith, 2008; Zelman et al., 2003). Clinical quality in this study measured through items assessing the complication rate (Griffith et al., 2006), the re-hospitalization rate, negative redundancies (e.g. redundant examinations) as well as compliance with defined quality standards. For measuring the financial performance of hospitals a huge variety of indicators has been suggested (McCracken et al., 2001; Pink et al., 2001). Based on prior research (Griffith et al., 2002; Gumbus et al., 2003; Walker and Dunn, 2006), items assessing the growth in revenue, process/case costs and the competitiveness of prices properly reflect the financial perspective and were thus chosen for this study. Items or indicators for the measurement of patient satisfaction vary only slightly in extant literature. Following Lovaglio (2011) and Meyer and Collier (2001) patient satisfaction was operationalized with items measuring the number of patient complaints on the one hand and patient satisfaction with the provided level of care and information and the smoothness of operations on the other. In order to test the relationships hypothesized in the research model, each construct was measured on a five-tiered Likert scales anchored between 1 (strongly disagree) and 5 (strongly agree). 